\title{
Effects of salinity structure on swimming behavior and harmful algal bloom formation in Heterosigma akashiwo, a toxic raphidophyte
}

\author{
R. N. Bearon ${ }^{1,3, *}$, D. Grünbaum ${ }^{1}$, R. A. Cattolico ${ }^{1,2}$ \\ ${ }^{1}$ School of Oceanography, Box 357940, University of Washington, Seattle, Washington 98195-7940, USA \\ ${ }^{2}$ Department of Biology, Box 351800, University of Washington, Seattle, Washington 98195-1800, USA \\ ${ }^{3}$ Present address: Department of Mathematical Sciences, University of Liverpool, Liverpool L69 7ZL, UK
}

\begin{abstract}
The formation of toxic surface blooms of the motile raphidophyte Heterosigma akashiwo often occurs too quickly to be attributed to cell reproduction. Rapid appearance of surface blooms is more consistent with the hypothesis that a dispersed cell population aggregates at the surface due to a combination of physical factors and swimming behavior. Because of the frequent association of Heterosigma bloom formation with a decrease in surface salinity, we hypothesize that a layer of lowsalinity water over a high-salinity layer will suppress nearsurface vertical mixing and this halocline will enable up-swimming cells to rapidly aggregate at the surface. For this hypothesis to be viable, Heterosigma cells must be able to swim across salinity jumps of a sufficient magnitude to temporarily suppress vertical mixing. We tested whether this requirement is satisfied by using computerized video analysis to quantify swimming behavior and vertical distribution of Heterosigma within a vertical salinity structure. Swimming behavior is affected by the presence of a salinity jump and depends on the strength of the jump: cells stopped swimming upwards and aggregated below a fresh water interface; cells reduced upward swimming speed with a salinity jump from 28 to $8 \%$, and upward swimming speed was unchanged in cells encountering a salinity jump from 28 to $16 \%$. We used observed swimming behaviors to parameterize a model of a 2-layer stratified water column in which vertical mixing is suppressed at the halocline and modeled by eddy diffusivity within each layer. The model predicts rapid aggregation of cells to the surface layer.
\end{abstract}

KEY WORDS: Motility - Salinity stratification $\cdot$ Harmful algal blooms $\cdot$ Heterosigma akashiwo

\section{INTRODUCTION}

Many harmful algal blooms (HABs) are characterized by a rapid and highly localized accumulation of toxic cells at high population densities. These increases in cell concentrations may be caused by a variety of mechanisms, including rapid cell division or synchronized emergence from resting stages that are resident in sediments. However, some HABs appear so rapidly that changes in overall numbers of cells are not large enough to account for observed increases in local cell population densities. In these cases, alternative mechanisms must drive the movement and concentration of pre-existing, but previously dispersed, cell popula- tions. These alternatives include the interaction of advective transport of the alga by environmental flows with the behavior of the alga itself (swimming, sinking and floating) (Franks 1997). Of these mechanisms, the contribution of swimming behavior to HAB formation is possibly the least well understood. We hypothesize that in combination with structural features of the water column, swimming can strongly promote HABs through shifts in population distribution.

In this report, we attempt to gain predictive insights into the process of cell accumulation by active swimming. The focal organism in this study is Heterosigma akashiwo, a raphidophyte that forms toxic surface blooms in temperate waters worldwide (Smayda 1998). 
Previous studies have shown that salinity is an important environmental cue for initiating Heterosigma blooms, and also alters Heterosigma's toxicity levels (Haque \& Onoue 2002). The formation of Heterosigma blooms has been associated with fresh water run-off and a reduction in salinity to below 15\% (Taylor \& Haigh 1993). In the laboratory, Heterosigma cells aggregate at the top of test tubes that contain seawater overlaid with distilled water (Hershberger et al. 1997). It has been hypothesized that similar aggregation at a fresh water interface may explain the formation of observed dense surface aggregations of Heterosigma after a sudden rainstorm or heavy runoff from rivers (Hershberger et al. 1997).

We have previously quantified the swimming behavior of Heterosigma akashiwo (Bearon et al. 2004). In a laboratory chamber stabilized by a weak salinity gradient, Heterosigma cells have a strong tendency to swim upwards with mean speeds of up to $100 \mu \mathrm{m} \mathrm{s}^{-1}$ (roughly $1 / 3 \mathrm{~m} \mathrm{~h}^{-1}$ ), and consequently aggregate at the upper surface of the chamber. In a natural population of Heterosigma cells, this behavior would cause a large fraction of the cell population to accumulate in a dense surface aggregation over the course of a few hours or days, provided the water column lacks significant advective transport or turbulent mixing. Consistent with this expectation, Heterosigma populations have been observed in the field to undergo substantial vertical movements on short time scales (Yamochi \& Abe 1984, MacKenzie 1991). However, most water columns that contain Heterosigma cells also possess advective transport or turbulent mixing. In these cases, surface accumulations through up-swimming would only occur if these dispersive mechanisms were suppressed, or if swimming were vigorous enough to overcome them.

The presence of a surface layer of low-salinity water represents one mechanism by which vertical advection and mixing could be temporarily suppressed. Cells that are transported by turbulence into contact with the surface layer and swim upwards into the layer would not be re-mixed downwards. This mechanism could cause rapid cellular aggregation to occur despite the presence of turbulent mixing in other parts of the water column. However, low salinities often suppress swimming and may be osmotically deleterious to many marine algae (Aizdaicher 1991, Erga et al. 2003). Thus, the hypothesis of HAB formation through behavioral accumulation is viable only within a range of salinities that is low enough to suppress turbulent mixing, but not so low as to have strong negative impacts on cell behavior or survival. Determining this range could provide useful predictions about the timing and location of HAB formation by motile algae.

We investigated the swimming behavior and consequent distribution of Heterosigma cells that were exposed in the laboratory to jumps in salinity similar to those that would be encountered in the field when the alga transits from lower high-salinity layers to upper low-salinity layers. Cells were inserted into the base of a chamber containing a vertical salinity structure, with high salinity $(28 \%)$ in the lower part, and low salinity $(0,8$, or $16 \%)$ in the upper part. We quantified the swimming behavior and distribution of these cells as functions of time and position at very high resolution using computerized video motion analysis. The observed behaviors were then used to construct a model of Heterosigma cell distributions in salinitystructured water columns. Finally, we assessed the model results in the context of prior demographic information about Heterosigma and other phytoplankton species, to generate predictions of conditions most likely to favor the formation of surface toxic blooms.

\section{MATERIALS AND METHODS}

Heterosigma akashiwo cells, strain CCMP452 (Provasoli Guillard Center for Culture of Marine Phytoplankton), were cultured in artificial seawater medium, O-3 (McIntosh \& Cattolico 1978) at $20^{\circ} \mathrm{C}$, light intensity 40 to $70 \mu \mathrm{mol}$ quanta $\mathrm{m}^{-2} \mathrm{~s}^{-1}$, and synchronized via a 12:12 h light:dark photoperiod. Exponentially growing cells were visualized swimming freely in a $30 \mathrm{~cm}$ tall by $6 \mathrm{~cm}$ internal diameter (volume $850 \mathrm{ml}$ ) plexiglass observation chamber. Temperature in the chamber was maintained at $20^{\circ} \mathrm{C}$ with a thermal jacket connected to a circulating water bath. During experiments visible light was maintained on the 12:12 h light:dark photoperiod using warm white compact fluorescent bulbs placed directly over the observation chamber located in a room that was otherwise dark to prevent extraneous light cues. The light intensity varied from $45 \mu \mathrm{mol}$ quanta $\mathrm{m}^{-2} \mathrm{~s}^{-1}$ at the top of the chamber to $15 \mu \mathrm{mol}$ quanta $\mathrm{m}^{-2} \mathrm{~s}^{-1}$ at the base.

The chamber was filled via a peristaltic pump with artificial seawater diluted with fresh (de-ionized) water to generate a specified salinity structure. Three vertical structures were created, with salinity jump from $28 \%$ o to either 0 , 8 or $16 \%$. In each case, the lower part of the chamber was weakly stratified to suppress water motion, with salinity varying linearly from $30 \%$ at the base of the chamber to $28 \%$ at the base of the salinity jump. In the salinity jump to $0 \%, 200 \mathrm{ml}$ of fresh water overlaid the saltwater. In the salinity jump to $8 \%$, the upper part of the chamber was weakly stratified such that the top of the upper layer had a salinity of $7 \%$. The salinity jump to $16 \%$ was similar, except that the top of the upper layer had a salinity of $15 \%$. Previous work has shown that changes in salinity structure due to diffusion are negligible over the course of these experi- 
ments. We refer to the large jump in salinity as the halocline. For each salinity structure, the experiment was repeated in triplicate.

After the salinity structure was established, cells were slowly introduced at the base of the chamber via a $10 \mathrm{ml}$ syringe attached to a glass tube of internal diameter approximately $2 \mathrm{~mm}$. Care was taken to minimize the shear stress experienced by cells on introduction to the chamber. Cells were observed in a roughly $1 \mathrm{~cm}^{3}$ volume near the radial center of the chamber, with dark field illumination from an infrared (960 nm) light source (Ramsey Electronics, IR1), a COHU 4815-3000 camera and a Nikon Nikkor $60 \mathrm{~mm}$ f/2.8D lens with infrared filter. The camera and light source were mounted on a computer-controlled platform that enabled observations over the entire vertical extent of the chamber. Imaging with infrared light was independent of the visible light; thus, cells could be imaged equally well in the light or dark. Video was captured to a computer at $10 \mathrm{~Hz}$ and automatically analyzed using ImageJ and Matlab software to produce a data file of 2-dimensional cell trajectories. The upward speed of each trajectory, defined as the net vertical displacement divided by the duration of each trajectory, was analyzed to obtain the distribution of upward speeds at each vertical horizon. The number of cell trajectories observed was used as an estimate of relative cell concentration. In the first hour of each experiment, top-to-bottom profiles of cell swimming and concentration at $1 \mathrm{~cm}$ vertical increments were performed every $15 \mathrm{~min}$. After the first hour of observation, profiles were performed hourly at $2 \mathrm{~cm}$ increments for at least $12 \mathrm{~h}$.

In the numerical model of Heterosigma in a salinity-structured water column, the vertical distribution of cells evolves in time through the action of turbulent vertical mixing and upward swimming. The $10 \mathrm{~m}$ water column consists of a deep high-salinity layer and surface low-salinity layer. Turbulent eddies disperse cells within each layer, but are prevented from mixing cells between the layers because of the density difference structured by the jump in salinity. The turbulent mixing is modeled by eddy diffusivity, taken to be $\kappa=3 \times 10^{-3} \mathrm{~m}^{2} \mathrm{~s}^{-1}$ within each layer, $\mathrm{a}$ typical value in Puget Sound coastal waters where Heterosigma is observed to bloom (Lavelle et al. 1991, Mickett et al. 2004). The vertical mixing barrier is modeled by setting the eddy diffusivity equal to zero at the halocline. The upward swimming speed is taken from our observations in the $30 \mathrm{~cm}$ high experimental chamber. We assume that the turbulent vertical mixing does not alter the swimming behavior, and that swimming behavior observed in a $30 \mathrm{~cm}$ chamber is representative of swimming in a larger $10 \mathrm{~m}$ column. Initially, cells are distributed through- out the lower high-salinity layer according to the equilibrium balance between up-swimming and eddy diffusivity. At time $t=0$ the surface layer is added, into which cells are able to swim. The subsequent distribution of cells is computed numerically as the solution to an advection-diffusion equation, where advection represents mean up-swimming, and diffusion represents eddy diffusivity, with no flux boundary conditions at the top and bottom. In the numerical scheme, diffusion terms are calculated with centered differences, advection with upwind differences, and time stepping was done using an AdamsBashforth-Moulton prediction-corrector method.

\section{RESULTS}

\section{Swimming behavior and spatial distribution of cells in chamber with salinity structure}

In all our experiments, Heterosigma akashiwo cells swam upwards in the weakly stratified lower part of the chamber, which lies below the halocline. Our experimental methods rely on weak salinity gradients to stabilize the water column, and strong behavioral responses to those gradients would affect our results. To determine whether the upward swimming was in response to the slight salinity gradients, we observed $H$. akashiwo cells in a darkened, unstratified, uniform-salinity column. Dense surface aggregations of H. akashiwo cells formed in the absence of both light and salinity gradient cues (Fig. 1). These results show that the up-swimming behavior we observed in the lower layer of our experimental chamber was not simply an artifact caused by the presence of a weak salinity gradient.

In the stratified columns, when the cells encountered the halocline, the swimming behavior and resultant spatial distribution of cells was affected by the strength of the halocline (see Figs. 2A, 3A \& 4A).

Salinity jump from 28 to $0 \%$

Cells rapidly aggregated below a freshwater interface (Fig. 2). Within the first hour of inserting cells at the base of the chamber, cells began to aggregate at the halocline, approximately $16 \mathrm{~cm}$ above the insertion point. This aggregation developed such that within $2 \mathrm{~h}$ from the start of the experiment (e.g. at 13:59 h), the relative cell concentration in the aggregation was 10-fold higher than typical cell concentrations below the halocline earlier in the experiment (e.g. at 12:29 h). This result is a conservative estimate of cell concentration in the aggregation. From video images we saw 


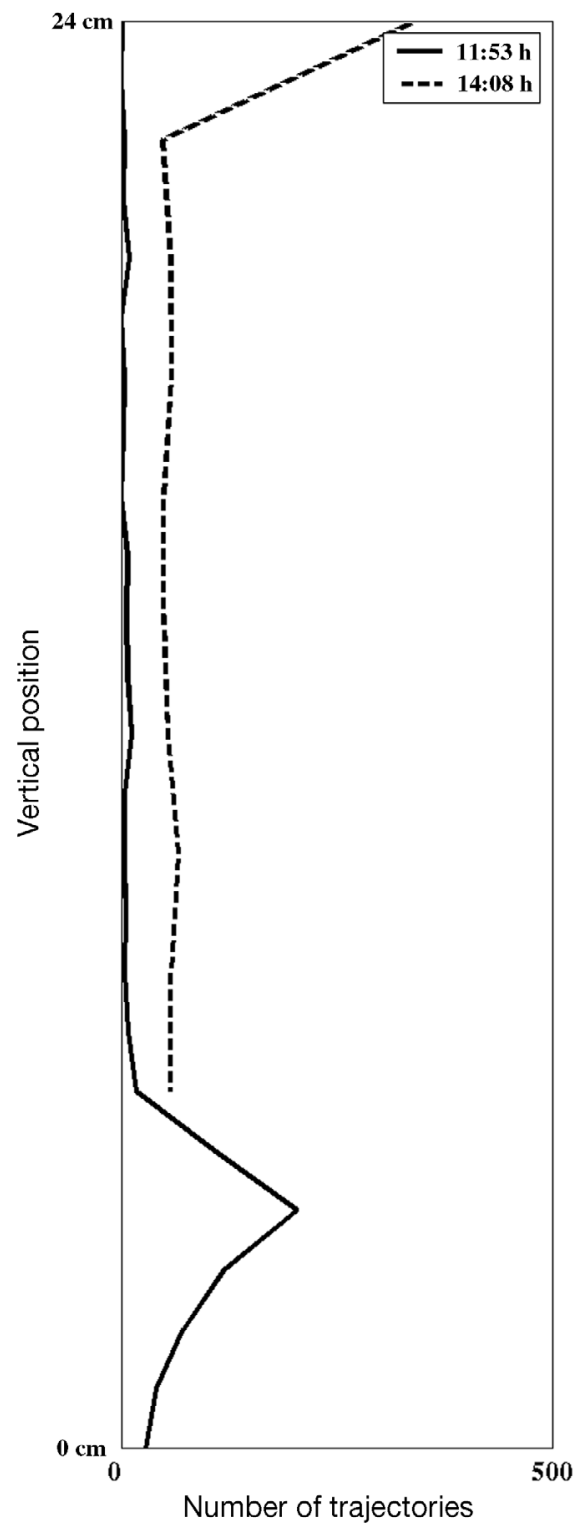

Fig. 1. Heterosigma akashiwo. Cell distributions in unstratified column in the dark. Vertical distribution of relative cell population density at the beginning of the experiment $(11: 53 \mathrm{~h})$ and ca. $2 \mathrm{~h}$ later $(14: 08 \mathrm{~h})$. In the absence of salinity gradients or overhead lighting, cells initially inserted close to the base of the column migrated upwards and aggregated at the surface

extremely high concentrations of cells in the aggregation which the analysis algorithm may not have fully resolved. Aggregation at the halocline occurred because cells stopped actively swimming on encountering the salinity jump from 28 to $0 \%$ (Fig. 2D,F).

The suspension of motility and aggregation at the halocline persisted for at least $12 \mathrm{~h}$, when the experiment was terminated. Heterosigma cells are typically denser than seawater: Watanabe (1982) gives a range
1.10 to $1.146 \mathrm{~g} \mathrm{~cm}^{-3}$; and Wada et al. (1985) give a range 1.05 to $1.12 \mathrm{~g} \mathrm{~cm}^{-3}$. Based on Stokes' law, in media of $28 \%$ salinity, approximately spherical cells of $10 \mu \mathrm{m}$ diameter and $1.10 \mathrm{~g} \mathrm{~cm}^{-3}$ density that ceased flagellar beating would sink at $4 \mu \mathrm{m} \mathrm{s}^{-1}$ (roughly $1 \mathrm{~cm} \mathrm{~h}^{-1}$ ) This sinking rate is not consistent with our observations at the freshwater interface. We hypothesize that cells penetrating into fresh or nearly fresh water stop flagellar beating, and also substantially decrease their densities and increase their drag through swelling, effectively trapping cells at or near the freshwater interface.

Salinity jump from 28 to $8 \%$ and from 28 to $16 \%$

Cells encountering an intermediate salinity jump (28 to $8 \%$ o) aggregated at the halocline within the first hour of the experiment (Fig. 3). At the example time point given in Fig. 3, the mean upward speed was reduced from approximately $45 \mu \mathrm{m} \mathrm{s}^{-1}$ below the halocline to $17 \mu \mathrm{m} \mathrm{s}^{-1}$ at the halocline, though some cells were able to swim upwards through the halocline with speeds as high as $100 \mu \mathrm{m} \mathrm{s}^{-1}$. At the example time point given in Fig. 3, cells were observed to swim actively above the halocline, with mean upward speed of approximately $21 \mu \mathrm{m} \mathrm{s}^{-1}$. Video observations showed that cells swam up into the top horizon containing the air-fluid interface. However, optical artifacts at the air-water interface prevented reliable enumeration of cell trajectories close to the surface. The differences in estimated total numbers of cells over the course of experiments are likely due to cells that could not be counted because they were too close to the air-water interface.

Cells encountering a weak salinity jump ( 28 to $16 \%$ ) displayed no change in swimming behavior, nor did they aggregate at the halocline (Fig. 4).

\section{Swimming speeds and cell sizes}

To determine whether the temporary aggregation at the 28 to $8 \%$ halocline was due to a reduction in cell swimming speed as cells encountered the sudden sharp decrease in salinity, we compared cell trajectories observed below and above the haloclines in all the experiments with salinity jump from 28 to $8 \%$. Crossing a salinity jump of 28 to $8 \%$ resulted in significant reduction of upward swimming speed (Fig. 5A).

We hypothesize that when cells swam through the salinity jump from 28 to $8 \%$, the reduction in swimming speed occurred because individual cells increased in size as part of a long-term osmotic adjustment to different salinity. According to this hypothesis, the change in speed results from a change in fluid drag, with swimming effort unchanged but swimming 


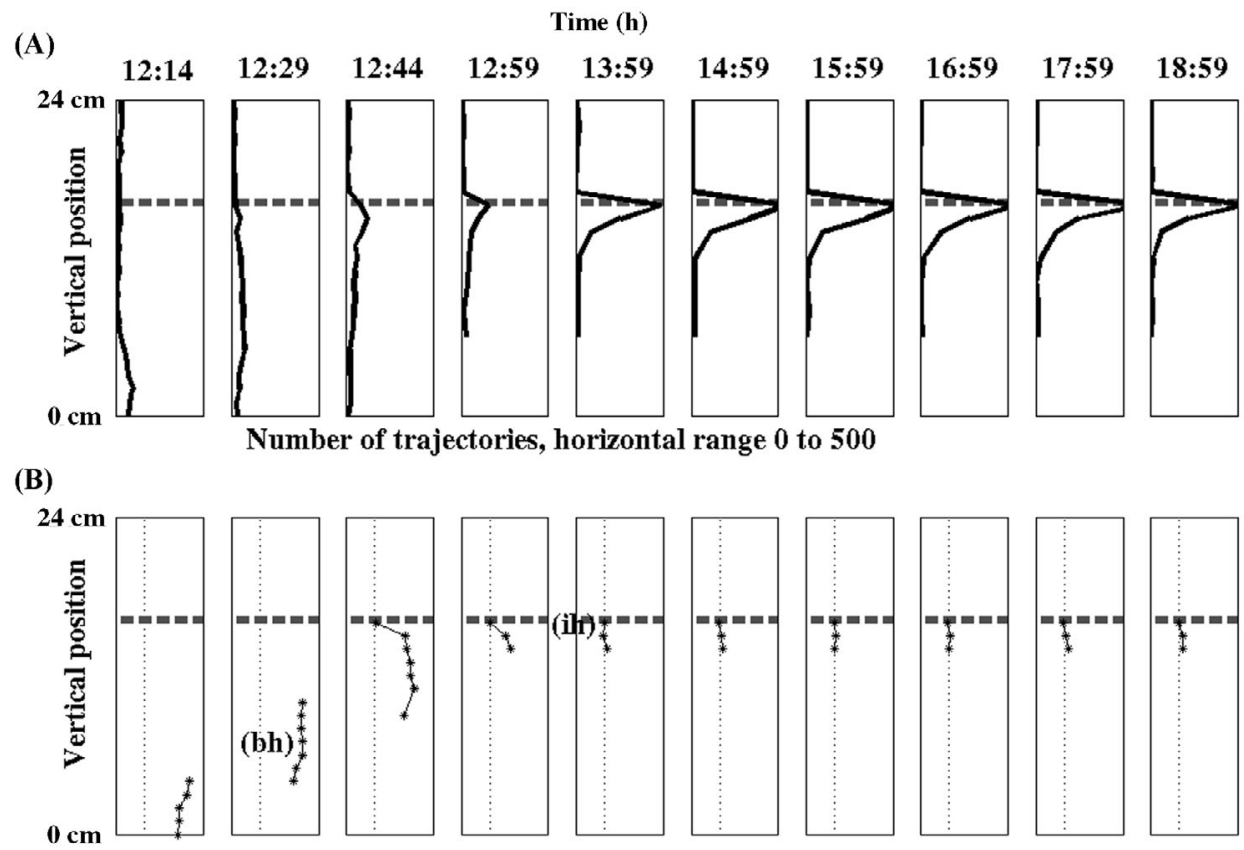

Mean upward speed, horizontal range -50 to $100 \mu \mathrm{m} \mathrm{s}^{-1}$

(C)

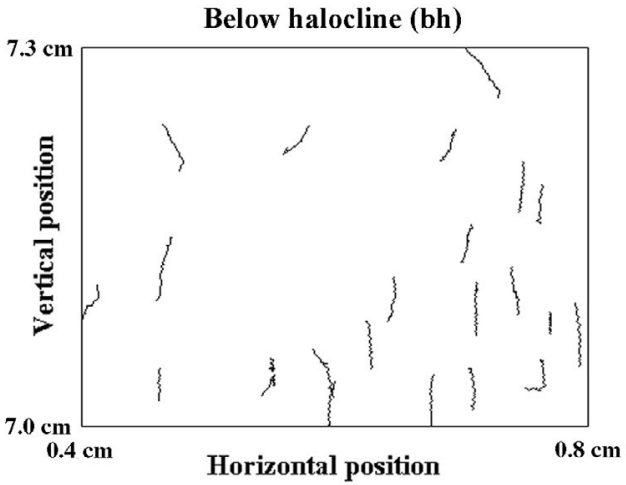

(E)

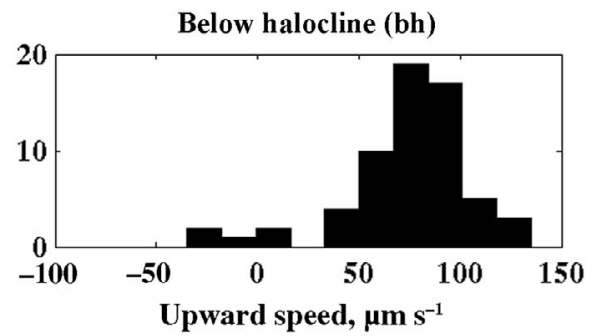

(D)

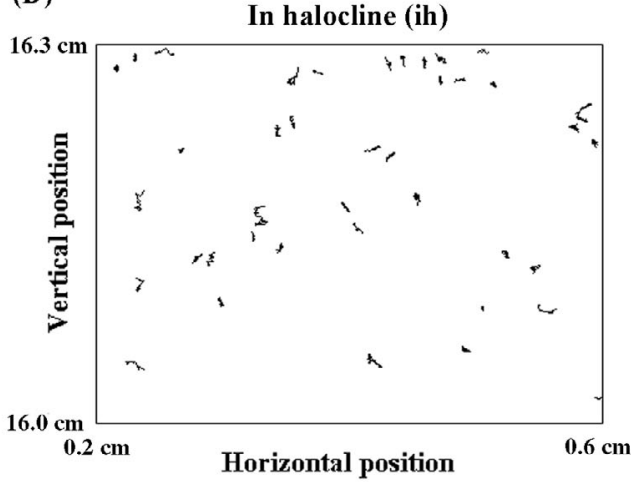

(F)

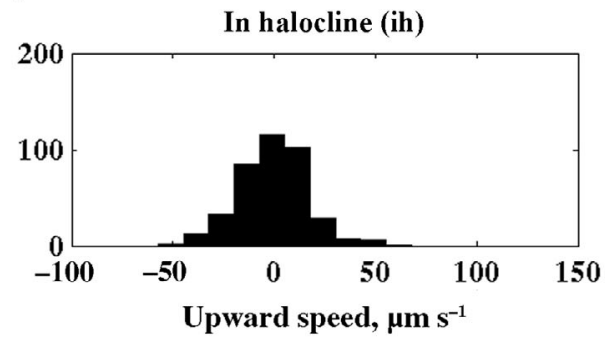

Fig. 2. Heterosigma akashiwo. Cell distributions and speeds across a 28 to $0 \%$ halocline. (A) Time series of the vertical distribution of relative cell population density, from the beginning of the experiment (12:14 h) to approximately $7 \mathrm{~h} \mathrm{later.} \mathrm{In} \mathrm{each} \mathrm{subplot,}$ the horizontal axis is from 0 to 500 cell trajectories observed in a fixed time interval $(10 \mathrm{~s})$. The halocline (indicated by the horizontal dashed grey line) marks the lower extent of the upper, fresher layer. (B) Time series of mean upward cell speed, for horizons in which at least 50 cell trajectories were observed. In each subplot, the horizontal axis is -50 to $100 \mu \mathrm{m} \mathrm{s}{ }^{-1}$; vertical dotted line indicates zero mean upward speed. (C) Typical cell trajectories observed in the weakly stratified water below the halocline (bh, $7 \mathrm{~cm}$ horizon, time 12:29 h). (D) Typical cell trajectories in the halocline (ih, $16 \mathrm{~cm}$ horizon, time 13:59 h). Trajectories shown in (C) and (D) are all of 50 frames duration. (E) Distribution of upward speeds (mean $=73 \mu \mathrm{m} \mathrm{s}^{-1}$ ) for all trajectories at the $7 \mathrm{~cm}$ horizon (bh) at time 12:29 h. (F) Distribution of upward speeds (mean $=-0.6 \mu \mathrm{m} \mathrm{s}^{-1}$ ) for all trajectories at the $16 \mathrm{~cm}$ horizon (ih) at time 13:59 $\mathrm{h}$. Time and position for the bh observations of (C) and (E) and the ih observations of (D) and (F) are indicated in (B) 
(A)

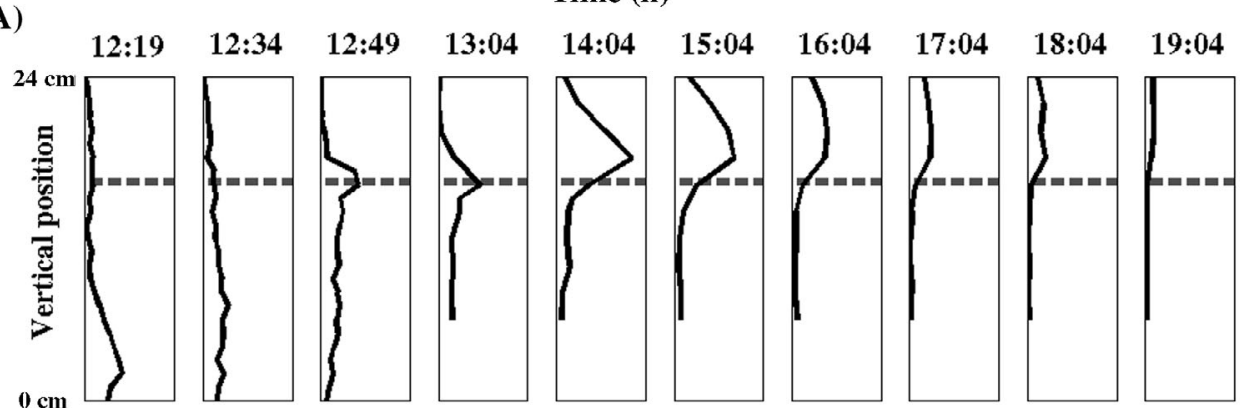

(B)

Number of trajectories horitontal range 0 to 500
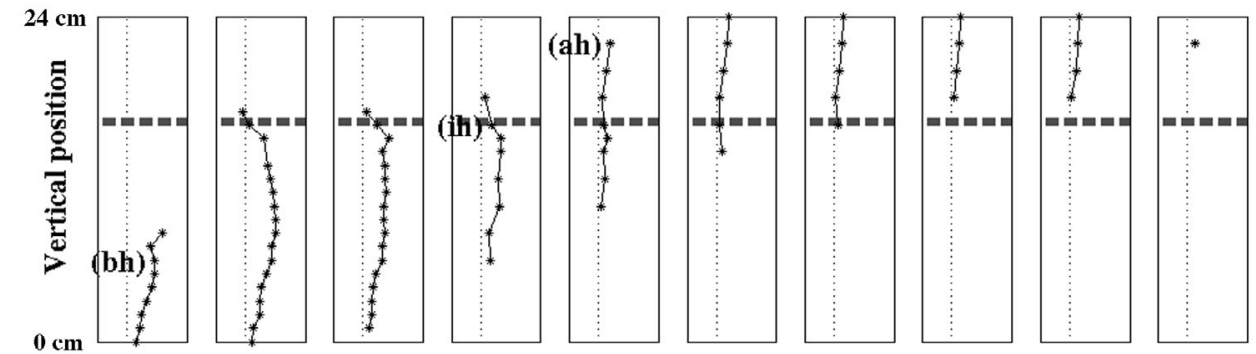

Mean upward speed, horizontal range -50 to $100 \mu \mathrm{m} \mathrm{s}^{-1}$

(C)

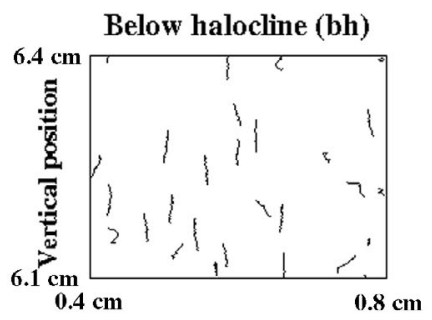

Horizontal position

(F)

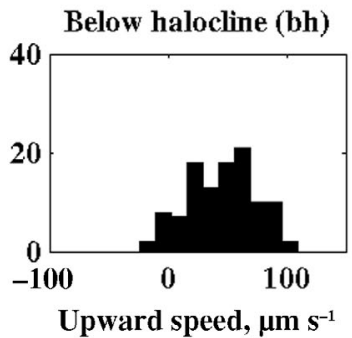

(D)

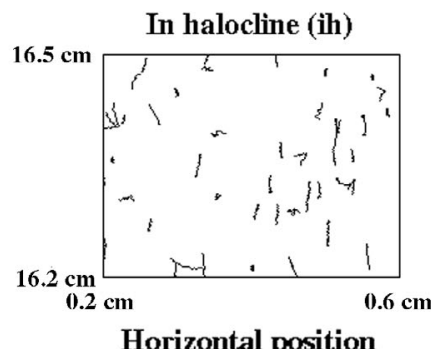

(G)

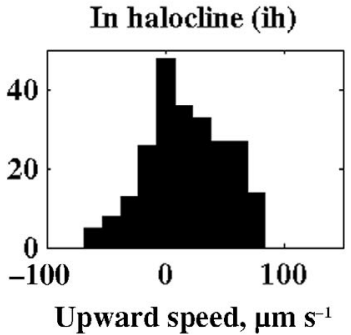

(E)

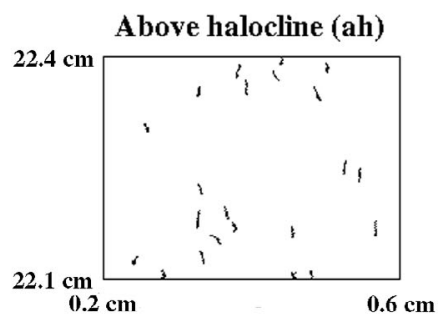

Horizontal position

(H)

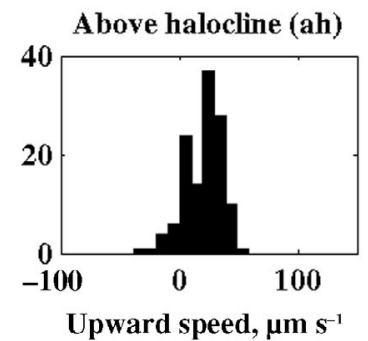

Fig. 3. Heterosigma akashiwo. Cell distributions and speeds across a 28 to $8 \%$ halocline. (A) Time series of the vertical distribution of relative cell population density, from the beginning of the experiment $(12: 19 \mathrm{~h})$ to approximately $7 \mathrm{~h}$ later. (B) Time series of mean upward cell speed. (C) Typical cell trajectories below the halocline (bh, $6 \mathrm{~cm}$ horizon, time 12:19 h). (D) Typical cell trajectories in the halocline (ih, $16 \mathrm{~cm}$ horizon, time 13:04 h). (E) Typical cell trajectories above the halocline (ah, $22 \mathrm{~cm}$ horizon, time 14:04 h). (F) Distribution of upward speeds (mean $=45 \mu \mathrm{m} \mathrm{s}^{-1}$ ) for all trajectories at the $6 \mathrm{~cm}$ horizon (bh) at time 12:19 h. (G) Distribution of upward speeds (mean $=17 \mu \mathrm{m} \mathrm{s}^{-1}$ ) for all trajectories at the $16 \mathrm{~cm}$ horizon (ih) at time 13:04 h. (H) Distribution of upward speeds $\left(\right.$ mean $=21 \mu \mathrm{m} \mathrm{s}^{-1}$ ) for all trajectories at the $22 \mathrm{~cm}$ horizon $(\mathrm{ah})$ at time 14:04 $\mathrm{h}$. Time and position for the ah observations of $(\mathrm{E})$ and $(\mathrm{H})$ are indicated in (B). Additional details as in Fig. 2 
(A)

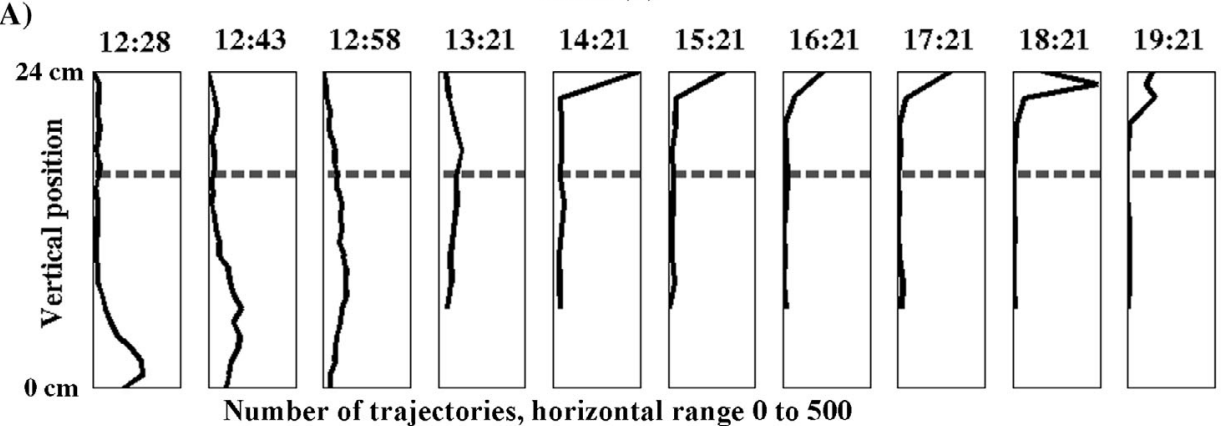

(B)

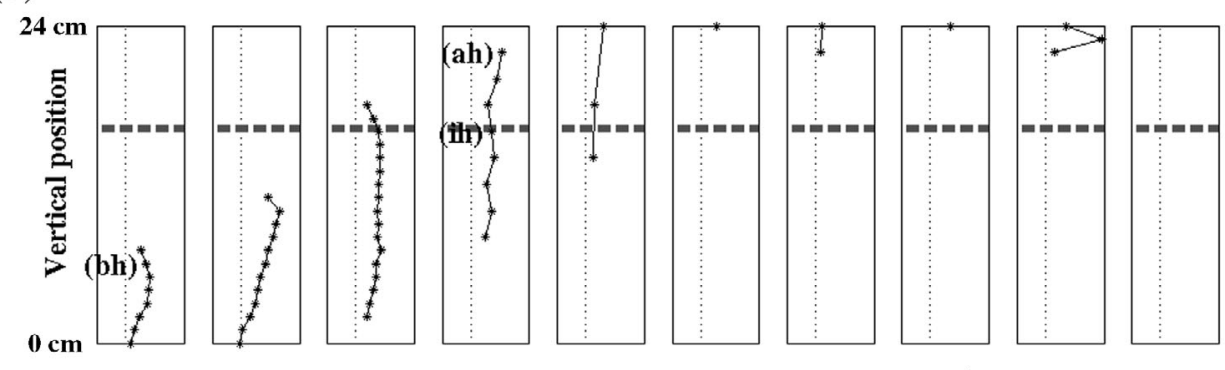

Mean upward speed, horizontal range -50 to $100 \mu \mathrm{m} \mathrm{s}^{-1}$

(C)

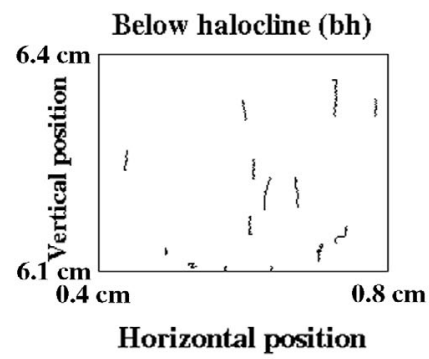

(F)

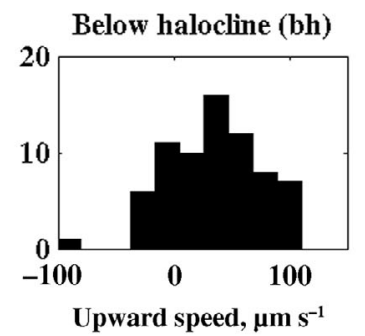

(D)

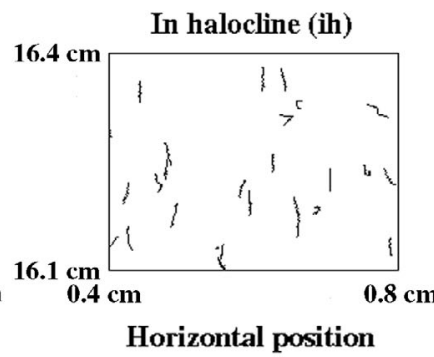

(G)

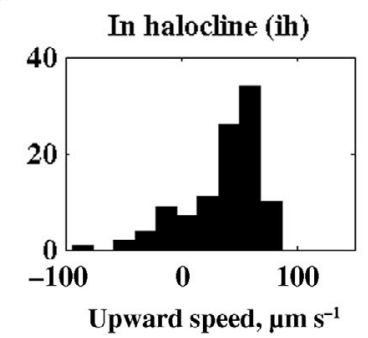

(E)

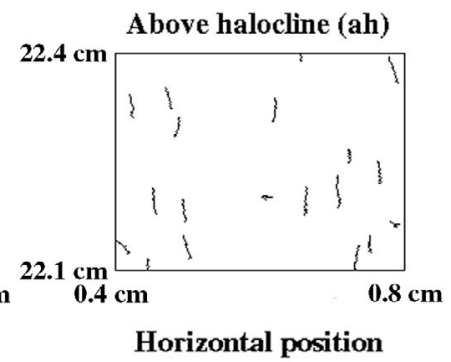

(H)

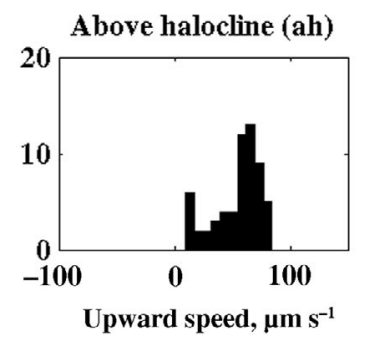

Fig. 4. Heterosigma akashiwo. Cell distributions and speeds across a 28 to $16 \%$ halocline. (A) Time series of the vertical distribution of relative cell population density, from the beginning of the experiment $(12: 28 \mathrm{~h})$ to approximately $7 \mathrm{~h}$ later. (B) Time series of mean upward cell speed. (C) Typical cell trajectories below the halocline (bh, $6 \mathrm{~cm}$ horizon, time 12:28 h). (D) Typical cell trajectories in the halocline (ih, $16 \mathrm{~cm}$ horizon, time 13:21 h). (E) Typical cell trajectories above the halocline (ah, $22 \mathrm{~cm}$ horizon, time 13:21 h). (F) Distribution of upward speeds (mean $=35 \mu \mathrm{m} \mathrm{s}^{-1}$ ) for all trajectories at the $6 \mathrm{~cm}$ horizon (bh) at time 12:28 h. (G) Distribution of upward speeds (mean $=37 \mu \mathrm{m} \mathrm{s}^{-1}$ ) for all trajectories at the $16 \mathrm{~cm}$ horizon (ih) at time 13:21 h. (H) Distribution of upward speeds $\left(\right.$ mean $=55 \mu \mathrm{m} \mathrm{s}^{-1}$ ) for all trajectories at the $22 \mathrm{~cm}$ horizon $(\mathrm{ah})$ at time 13:21 h. Time and position for the ah observations of (E) and (H) are in (B). Additional details as in Fig. 2 
(A)

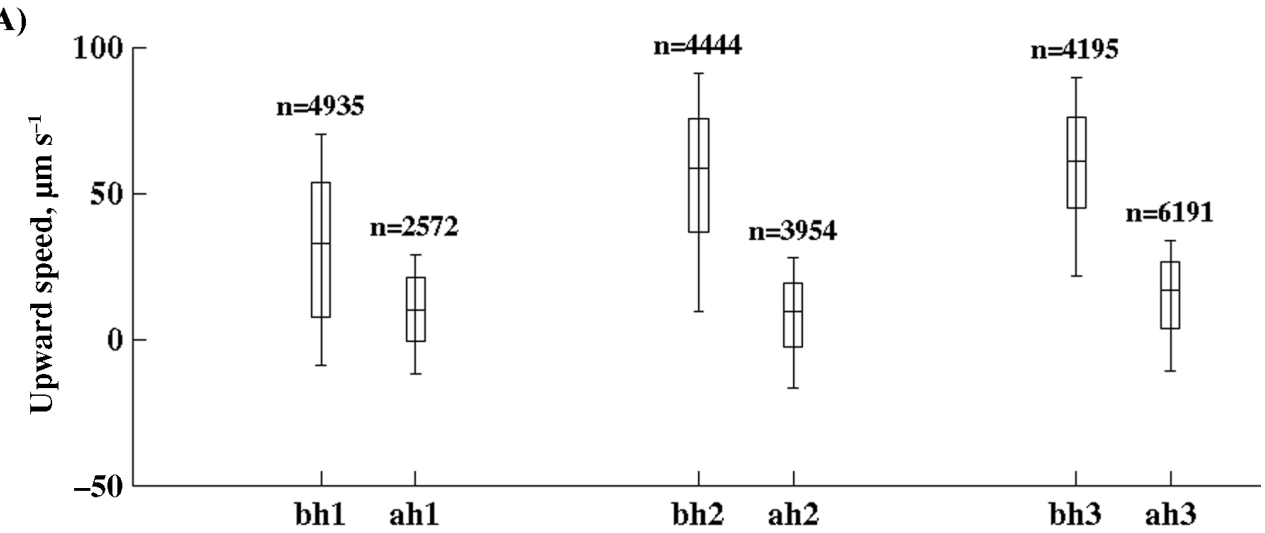

(B)

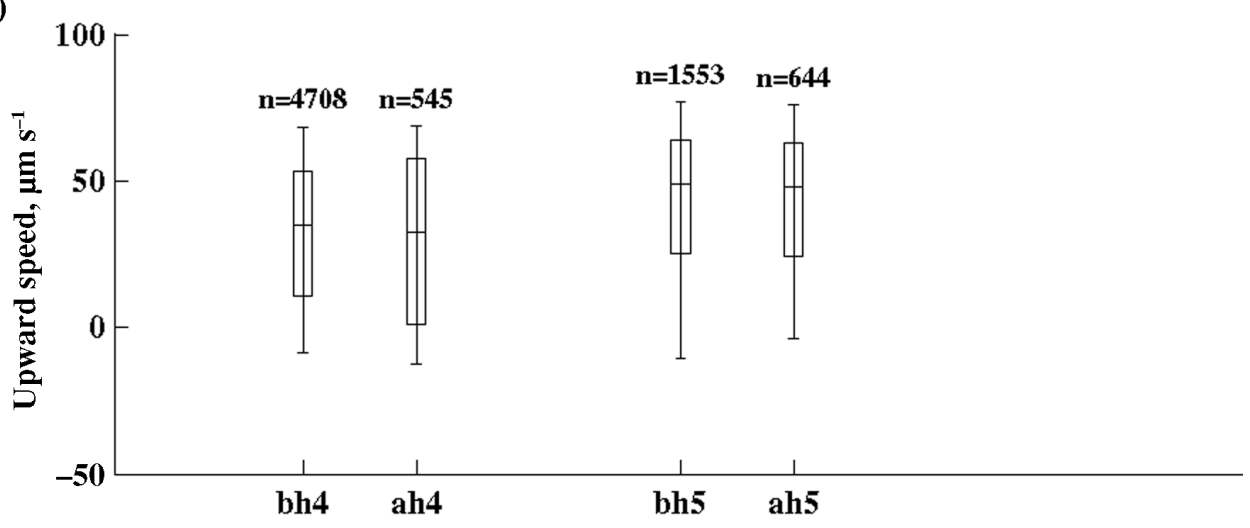

Fig. 5. Heterosigma akashiwo. Cell speeds below the halocline (bh) and above the halocline (ah). (A) Comparison of the upward speed of trajectories below and above the salinity jump 28 to $8 \%$. Trajectory speeds for bh are given for the first $4 \mathrm{~h}$ of 3 replicate experiments (bh1 to bh3), with corresponding ah speeds (ah1 to ah3). Cell trajectories are included in the analysis only if at least 50 cell trajectories are identified at a particular horizon and time point. Observations within $1 \mathrm{~cm}$ of the surface are not included in the analysis because of additional complexity in swimming behavior and visualization at the surface. Box plots indicate the 0.1 , $0.25,0.5,0.75$ and 0.9 quantiles for each set of $\mathrm{n}$ trajectories. Upward speed significantly decreases as cells swim from water of salinity 28 to $8 \%$, with mean values dropping from 31 to 9, 54 to 7 and 58 to $14 \mu \mathrm{m} \mathrm{s}^{-1}$ in Expts 1 to 3 respectively. (B) Equivalent data for 2 replicate experiments (Expts 4 and 5) with salinity jump 28 to $16 \%$; upward speed is unchanged as cells swim across this salinity jump (mean upward speed of 32,30,42 and $42 \mu \mathrm{m} \mathrm{s}^{-1}$ for bh4, ah4, bh5 and ah5 respectively). Note that no data are available for the strong salinity jump treatment (Fig. 1) because no cells penetrated above the halocline

capacity significantly reduced. This hypothesis predicts that slow swimming is a long-term characteristic of Heterosigma cells at low salinities, and is not necessarily a beneficial behavioral characteristic. To test this hypothesis, we measured the variation of cell diameter with salinity in $H$. akashiwo cells. Cells that were actively dividing in O-3 media of salinity $30 \%$ had modal cell diameter 10 to $12 \mu \mathrm{m}$ (approximate volume $700 \mathrm{~mm}^{3}$ ). In contrast, cells actively dividing in O-3 diluted with fresh water to a salinity of $8 \%$ had modal cell diameter to 17 to $19 \mu \mathrm{m}$ (approximate volume $3000 \mathrm{\mu m}^{3}$ ), a 50 to $100 \%$ increase in diameter. This observation is in agreement with Hershberger et al. (1997), who reported an increase in Heterosigma cell volume after encounter with lower salinity surface water. At the small scale of swimming cells, for a given propulsive force, swimming speed is inversely proportional to cell diameter. Based on the observed increase in cell diameter, we thus predict speed decreases of 30 to $50 \%$, consistent with decreases observed in the 28 to $8 \%$ treatment.

In contrast to the 28 to $8 \%$ halocline, cells showed no reduction in upward swimming speed as they passed through the 28 to $16 \%$ halocline (Fig. 5B). This result suggests that cells did not undergo significant swelling in response to this large salinity change.

\section{Model to predict the formation of high cell concentration surface aggregations}

To investigate the effect of salinity structure on swimming and the formation of surface aggregations in the natural environment where turbulent mixing is present, we modeled the vertical distribution of cells in a water column that has a high-salinity lower layer and 
low-salinity upper layer (Fig. 6). Cells were initially well-mixed in the lower layer because the action of turbulence overwhelmed the ability of cells to swim upwards. Following the addition of a low-salinity layer of surface water, cells began to aggregate at the surface. This concentration of cells occurred because turbulent mixing was suppressed across the halocline and
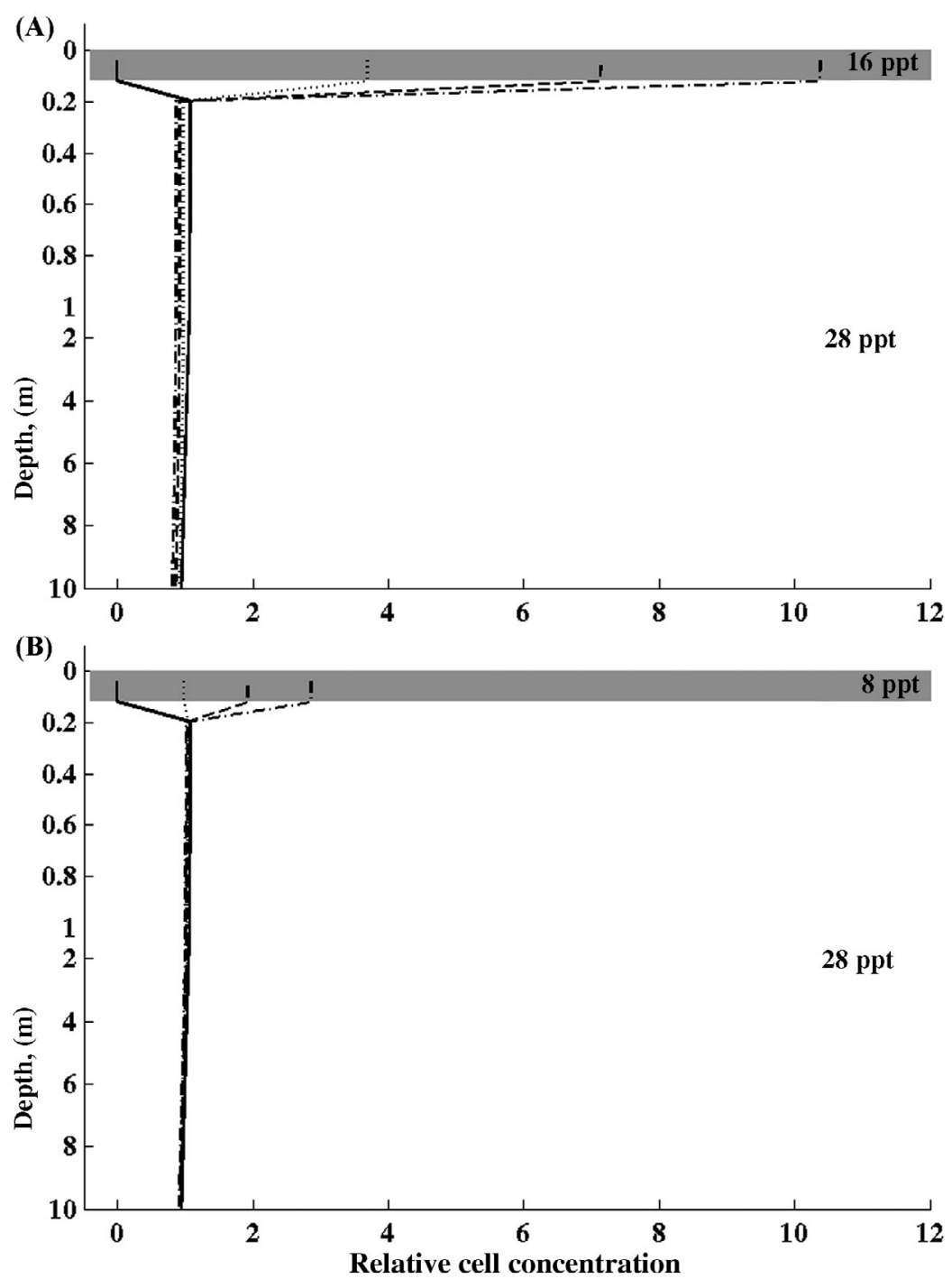

Fig. 6. Heterosigma akashiwo. Model results for aggregation of cells in lowsalinity surface layer. Vertical distribution of cells at time $t=0$ (solid line), $t=4 \mathrm{~h}$ (dotted line), $t=8 \mathrm{~h}$ (dashed line) and $t=12 \mathrm{~h}$ (dot-dash line). Shaded region marks the low-salinity surface layer which overlays the lower high-salinity $(28 \%$ ) layer. Scale on the depth axis is expanded above $1 \mathrm{~m}$ for clearer visualization of the surface layer. Cell concentration is given relative to an initial distribution which has unit mean in the lower layer. Eddy diffusivity within each layer is $\mathrm{K}=3 \times 10^{-3} \mathrm{~m}^{2} \mathrm{~s}^{-1}$, and is zero at the interface. Mean up-swimming speed is $40 \mu \mathrm{m} \mathrm{s}^{-1}$ in the lower layer. (A) Surface layer has salinity $16 \%$. Based on the experimental observations presented in Fig. 4, behavior is unchanged as cells swim into this surface layer; thus, up-swimming speed remains at $40 \mu \mathrm{m} \mathrm{s}^{-1}$ in the surface layer. (B) Surface layer has salinity $8 \%$. Based on the experimental observations presented in Fig. 4, up-swimming speed is reduced to $10 \mathrm{~mm} \mathrm{~s}^{-1}$ in this surface layer so cells which swam upwards into the surface layer remained trapped in the upper layer. Because vertical by turbulence overwhelmed swimming within aggregated at the surface was determined by the cells swam across the halocline. For example, in our numerical simulation with salinity jump of 28 to $16 \%$ (Fig. 6A), cells swam across the halocline with a speed of $40 \mu \mathrm{m} \mathrm{s}^{-1}$ and the relative cell concentration in the surface layer increased from 0 to $4 \mathrm{~m}^{-1}$ in $4 \mathrm{~h}$. Based on our swimming observations, a salinity jump of 28 to $8 \%$ o was sufficient to cause cells to slow down by a factor of 4 on encountering the low-salinity layer, and thus the relative cell concentration in the surface layer only increased from 0 to $1 \mathrm{~m}^{-1}$ in $4 \mathrm{~h}$ (Fig. 6B).

\section{DISCUSSION}

Ecological effects of HABs depend strongly on the spatial distribution of the algal cells. Patchy HAB structure likely affects a variety of densitydependent interactions within the local marine community, including competition, transmission of pathogens, cellto-cell signaling and exposure to allelopathic products. When cells are concentrated in surface aggregations, other organisms will be intermittently exposed to higher cell concentrations than if the same number of algal cells were more uniformly distributed in the water column. This exposure to high cell concentrations may cause these organisms to experience high levels of toxic substances, resulting in negative impacts much greater than would be expected from the spatially averaged toxin concentration.

Our experiments demonstrate that Heterosigma cells are able to swim through a salinity jump from 28 to $16 \%$ without changing swimming behavior. This capability suggests that in a stratified environment having a salinity distribution within this range, dense surface aggregations of Heterosigma will form due to up-swimming. Stronger haloclines can cause behavioral and 
physiological changes: A salinity jump from 28 to $8 \%$ results in a reduction in upward swimming speed. Such behavioral changes will alter the spatial distribution of cells, for example, delaying the formation of a surface aggregation. Cells are unable to swim into fresh water, and thus aggregations of cells are predicted not to form in fresh or very low-salinity surface layers. However, aggregations may form below such layers, if vertical mixing is sufficiently low.

Our observation that Heterosigma akashiwo cells cease swimming when exposed to physiological challenge is in agreement with others (Aizdaicher 1991, Han et al. 2002). On encountering fresher water, we hypothesize that cells also substantially decrease their densities and increase their drag through swelling, effectively trapping cells at or near the freshwater interface. Although this hypothesis is consistent with the aggregations and cell-size changes observed in our experiments, it is unclear whether remaining in an apparently stressful part of the environment is adaptive or a pathological by-product of responses that are more suitable to other circumstances.

Hershberger et al. (1997) hypothesized that Heterosigma cells swim to the surface in response to slight salinity gradients. The formation of surface aggregations in an unstratified column in the dark suggests that neither the salinity gradient nor the presence of overhead lighting affected up-swimming ability. Contrary to previous observations on the vertical migration of Heterosigma cells (Kohata \& Watanabe 1986), we did not observe cells to swim on average downwards at any time during the light-dark cycle. However, in our experiments, we have focused attention on the swimming behavior of exponentially growing cells, and it is quite probable that culture age and physiological state of the cells affect swimming behavior and migration patterns. Further variation may also be due to strainal differences in swimming behavior (Bearon et al. 2004).

Our numerical model extrapolates our experimental observations to make predictions about the formation of surface aggregations of cells in a water column that has salinity structure and turbulent vertical mixing. While turbulent mixing effectively disperses cells within both the surface and the underlying layers, turbulence also dramatically increases the rate at which cells encounter the interface between these layers. If we assume that active swimming acts as it did in our experiments to transport cells across the interface, the result is greatly enhanced cell concentration in the surface layer. Fresher surface water that comes from river run-off may contain more nutrients and enhance cell growth in the surface layer leading to further increase in cell concentrations. This mechanism for bloom formation requires wide salinity tolerance and strong swimming ability, both of which are evident in Heterosigma.
In this study, we have demonstrated that Heterosigma akashiwo can swim across a salinity jump of 28 to $16 \%$ into much fresher surface water with no change in swimming behavior. In contrast, in a similar study Tetraselmis sp. displayed delays in swimming due to changes in salinities of less than 1\%o (Erga et al. 2003). Previous studies demonstrate that Heterosigma is remarkably tolerant of a wide range of salinities, thus suggesting that Heterosigma cells will continue to thrive after swimming into fresher surface water. For example, Honjo (1993) reports in situ salinity concentrations during blooms that span 20 to $33 \%$, and in the laboratory Heterosigma has been grown successfully at a range of salinities <2 to $50 \%$ (Tomas 1978). Mahoney \& McLaughlin (1979) compared the influence of salinity on the growth of dominant phytoflagellate species in New York Harbor. They found that H. akashiwo preconditioned at $30 \%$ was able to grow at lower salinities (optimal growth at minimum salinity $10 \%$ ) than the other algal species examined (optimal growth at minimum salinity $24 \%$ ). In that and similar phytoplankton communities, we predict that the superior ability of Heterosigma to tolerate low salinity may result in the formation of unialgal surface aggregations of Heterosigma in a layer of low-salinity surface water.

Acknowledgements. The authors are grateful for support to R.N.B. and D.G. from NOAA Washington Sea Grant Program (NA040AR170032); and to R.A.C. from the NOAA Washington Sea Grant Program (NA16RG1044) and the University of Washington Royalty Research fund.

\section{LITERATURE CITED}

Aizdaicher NA (1991) Response to dilution of the unicellular alga Heterosigma akashiwo. Biol Morya 3:55-60

Bearon RN, Grünbaum D, Cattolico RA (2004) Relating celllevel swimming behaviors to vertical population distributions in Heterosigma akashiwo (Raphidophyceae), a harmful alga. Limnol Oceanogr 49:607-613

Erga SR, Dybwad M, Frette Ø, Lotsberg JK, Aursland K (2003) New aspects of migratory behavior of phytoplankton in stratified waters: effects of halocline strength and light on Tetraselmis sp. (Prasinophyceae) in an artificial water column. Limnol Oceanogr 48:1202-1213

Franks PJS (1997) Spatial patterns in dense algal blooms. Limnol Oceanogr 42:1297-1305

Haque SM, Onone Y (2002) Effects of salinity of growth and toxin production of a noxious phytoflagellate, Heterosigma akashiwo (Raphidophyceae). Bot Mar 45:356-363

Han MS, Kim YP, Cattolico RA (2002) Heterosigma akashiwo (Raphidophyceae) resting cell formation in batch culture: strain identity versus physiological response. J Phycol 38: 304-317

Hershberger PK, Rensel JE, Matter AL, Taub FB (1997) Vertical distribution of the chloromonad flagellate Heterosigma carterae in columns: implications for bloom development. Can J Fish Aquat Sci 54:2228-2234

Honjo T (1993) Overview on bloom dynamics and physiologi- 
cal ecology of Heterosigma akashiwo. In: Smayda TJ, Shimizu Y (eds) Toxic phytoplankton blooms in the sea. Elsevier, Amsterdam, p 33-41

Kohata K, Watanabe M (1986) Synchronous division and the pattern of diel vertical migration of Heterosigma akashiwo (Hada) (Raphidophyceae) in a laboratory culture tank. J Exp Mar Biol Ecol 100:209-224

Lavelle JW, Cokelet ED, Cannon GA (1991) A model study of density intrusions into and circulation within a deep, silled estuary-Puget Sound. J Geophys Res C96:16779-16800

MacKenzie L (1991) Toxic and noxious phytoplankton in Big Glory Bay, Stewart Island, New Zealand. J Appl Phycol 3: 19-34

Mahoney JB, McLaughlin JJA (1979) Salinity influence on the ecology of phytoflagellate blooms in lower New York Bay and adjacent waters. J Exp Mar Biol Ecol 37:213-223

McIntosh L, Cattolico RA (1978) Preservation of algal and higher plant ribosomal RNA integrity during extraction and electrophoretic quantitation. Ann Biochem 91:600-612

Mickett JB, Gregg MC, Seim HE (2004) Direct measurements of diapycnal mixing in a fjord reach - Puget Sound's Main Basin. Estuar Coast Shelf Sci 59:539-558

Editorial responsibility: Otto Kinne (Editor-in-Chief), Oldendorf/Luhe, Germany
Smayda TJ (1998) Ecophysiology and bloom dynamics of Heterosigma akashiwo (Raphidophyceae). In: Anderson DM, Cembellas AD, Hallegraeff GM (eds) Physiological ecology of harmful algal blooms. Springer-Verlag, Berlin, p 115-131

Taylor FJR, Haigh R (1993) The ecology of fish-killing blooms of the chloromonad flagellate Heterosigma in the strait of Georgia and adjacent waters. In: Smayda TJ, Shimizu Y (eds) Toxic phytoplankton blooms in the sea. Elsevier, Amsterdam, p 705-710

Tomas CR (1978) Olisthodiscus luteus (Chrysophyceae) I. Effects of salinity and temperature on growth, motility and survival. J Phycol 14:309-313

Wada M, Miyazaki A, Fujii T (1985) On the mechanisms of diurnal vertical migration behavior of Heterosigma akashiwo (Raphidophyceae). Plant Cell Physiol 26:431-436

Watanabe M (1982) The diurnal variations in the cell densities of Olisthodiscus luteus and Skeletonema costatum. Res Rep Natl Inst Environ Study 30:143-154

Yamochi S, Abe T (1984) Mechanisms to initiate a Heterosigma akashiwo red tide in Osaka Bay II. Diel vertical migration. Mar Biol 83:255-261

Submitted: January 21, 2005; Accepted: July 6, 2005

Proofs received from author(s): December 7, 2005 